\title{
Dispersants as marine oil spill treating agents: a review on mesoscale tests and field trials
}

\author{
Francois Merlin ${ }^{2 \dagger}$, Zhiwen Zhu ${ }^{1 \dagger}$, Min Yang ${ }^{1 \dagger}$, Bing Chen ${ }^{1}$, Kenneth Lee ${ }^{3}$, Michel C. Boufadel ${ }^{4}$, \\ Lisa Isaacman ${ }^{3}$ and Baiyu Zhang ${ }^{1 *}$
}

\begin{abstract}
The increasing oil demand and busy waterways highlight the importance of oil spill preparedness and responses. Dispersants attract attention as an effective response tool to manage the impacts of major spill incidents. Despite in-depth laboratory evaluations on the effectiveness of chemical dispersants and their impacts on the transportation and fate of spilled oils, how dispersant works at sea remains a question and calls for the tests with greater realism to validate laboratory results, bring in energy impacts, and evaluate dispersant application equipment. Mesoscale studies and field trials have thus been widely conducted to assist better spill response operations. Such research attempts, however, lack a systematic summary. This study tried to fill the knowledge gaps by introducing the mesoscale facilities developed to advance the understanding of dispersant effectiveness on various sea conditions. An up-to-date overview of mesoscale studies and field trial assessments of dispersant effectiveness has also been conducted. We ended this review by highlighting the importance of public perception and future research needs to promote the approval and application of dispersants in spill incidents.
\end{abstract}

Keywords: Dispersant effectiveness, Field trials, Mesoscale tests, Climate change, Oil spill response

\section{Background}

A large number of oils spilled into the marine environment naturally (e.g., natural seeps) or accidentally (e.g., from platform blowouts and tank or pipeline leaks) highlighted the importance of effective spill response technologies (Bi et al. 2021, Vahabisani et al. 2021). A warming climate opens the waterways in the Arctic region and highlights the potential oil spill incidents in the marine environment, caused by increasing Arctic oil storage, exploration, production, and shipping activities. Dispersant application, one of the most effective spill responses in the field, however, remains to be a topic of debate after

\footnotetext{
*Correspondence: bzhang@mun.ca

${ }^{\dagger}$ Francois Merlin, Zhiwen Zhu and Min Yang-co-first authors

${ }^{1}$ Northern Region Persistent Organic Pollutant Control (NRPOP)

Laboratory, Faculty of Engineering and Applied Science, Memorial

University, St. John's, NL A1B 3X5, Canada

Full list of author information is available at the end of the article
}

five decades from their first field application due to the mounting environmental concerns. Though dispersion of spilled oils occurrs naturally when waves and sea turbulence break surface oil slicks into oil droplets and then transfer those droplets into water columns, the sizes of the naturally dispersed oils droplets limit their stability in water column. Chemical dispersants thus are applied to enhance the rate and extent of dispersion and dilution of oils caused by wave actions (Cai et al. 2021). Dispersants consist of surfactants (effective agents that reduce the interfacial tension between oil and water and break oil slicks into small droplets), solvents, and other compounds. They can promote the generation of small oil droplets, which can be rapidly entrained into the water column without resurface, coalescence and reaching the coastal region (Zhu et al. 2020). Surface dispersant application, comparing to other response techniques, are believed to be efficient in removing floating oils, 
especially in terms of their application in remote areas, treating large size spill incidents, and reducing health risk to at-sea responders. After the record-setting application of dispersant in the Deepwater Horizon incident ( 2.1 million gallons), dispersant logistics and supply planning have been developed, and dispersant stockpile has been established by the petroleum industry. The strategic stockpile list includes the most widely investigated and applied dispersants Dasic Slickgone NS, Finasol ${ }^{\circledR}$ OSR 52 and Corexit 9500 A (Bejarano 2018). These dispersants have also become the most selected dispersants being investigated in mesoscale studies and field trials. To date, our understanding of the impacts of dispersant as a response tool has been greatly advanced by laboratory investigations and numerical simulations and optimizations. The impact of complex field conditions on dispersant effectiveness, which is difficult to be captured by bench studies, has also been explored in mesoscale in the past few years. The French Protecmar program and the British and Norwegian (NOFO) North Sea trials were conducted to validate the laboratory studies in the real field (Chapman et al. 2007; Lambert 2003). Canada also carried out sea trials to validate the applicability of dispersants (i.e., trials in Halifax (Gill et al. 1985) and Newfoundland (Gill and Ross 1981)). These programs made it possible to verify laboratory observations, develop materials and dispersant application equipment, and evaluate the operational efficiency of products and equipment under realistic conditions. The effects of dilution on dispersant fate and transport could also be observed. Those field results (e.g., concentration and distribution of dispersed oil, dissipation rate of the oil plume) are important to define the conditions of chemical dispersion application. The concentration of dispersed oils in water columns could be rapidly reduced from a few hundred ppm to less than $1 \mathrm{ppm}$ within a few hours of dispersant application (Lewis and Prince 2018). Through these studies, the integrated models and their submodels especially scaling of droplet size were validated, the response-decision making approaches were examined, and the linkages in complex ecosystems affected by oil were also uncovered. In addition, response personnel are benefited from these tests through familiarising themselves with the oil and response techniques. Similarly, field tests also offer an opportunity for the assessment of operational equipment and response effectiveness.

However, despite extensive reviews on the laboratory investigations on dispersants, and assessment of Deepwater Horizon Spill incidents, a systematic summary of mesoscale and field testing of dispersant effectiveness remains to be very limited. Therefore, this work summarized the research papers published between 2000 and 2020 to provide an up-to-date overview of mesoscale studies and field trials conducted for dispersant effectiveness assessment. The mesoscale facilities developed to facilitate the understanding of dispersant effectiveness on various sea conditions were introduced, studies conducted by those mesoscale facilities were summarized, and field trial assessments of dispersant effectiveness were elaborated. We ended this review with a discussion on the public perception and future research needs to promote the approval and application of dispersants in spill incidents.

\section{Mesoscale dispersant testing}

All the marine conditions cannot be realistically recreated in laboratory glassware because the size of the laboratory testing equipment is limited and cannot simulate/ mimic the infinite possibility of dilution which prevails in the open sea (Holder et al. 2015; Ross 2013). Also, it is challenging to carry out the sea trials (Merlin 2008). Thus, research teams developed mesoscale tests using medium-sized test facilities (e.g., tanks, canals, pools) in the lab or at the field under controlled conditions (Cui et al. 2020). Such tests could validate the bench-scale results and investigate the previously hard-to-access factors (e.g., wave, wind, etc.) in a more realistic manner. The key elements of the mesoscale testing facilities include their geometry, the agitation mode (e.g., wave generator), the control of temperatures (possibility of adjusting the ambient and water temperatures), the possibility of recreating the air circulation (wind), and the possibility of photo-oxidize the surface oil (solar light simulation). Other additional important points are the features in controlling and measuring the dispersion, the possibility of monitoring what occurs in the testing facility, and the possibility of dilution (changing the water content progressively by new sea water) (King et al. 2018).

In these facilities, almost the whole dispersion process can be reproduced, including oil release, application of the dispersant on the oil, dispersion of the oil under a steady agitation. To better target the dispersant application, the oil is often kept confined at the beginning of the test. Sometimes, the oil can be weathered in the facility prior to the test itself. Typically, a test consists in releasing the oil in the facility and applying the dispersant on the oil, starting the agitation, and then following the dispersion process. Usually, the dispersion is assessed and quantified by measuring the dispersion effectiveness $(\mathrm{DE})$. This is a parameter used to determine the effectiveness of chemical dispersant in dispersing spilled oils and has been applied as the most important criteria in the dispersant screening and approval process. It is also an important parameter that needs to be closely monitored in the field, as it directly related to whether or not to use chemical dispersants, and when to terminate the 
operations. The oil droplet size distribution is another parameter that has been widely investigated (Yang et al. 2020). This information is of great importance on the transportation and fate of chemically dispersed oils (e.g., resurface, oil-mineral aggregation, emulsification and biodegradation, etc.). Finally, dispersed oil concentrations in the water column (quantification of the dispersion) and/or measuring the distribution of the dispersed oil droplet diameter and their composition are sometimes determined (Faksness et al. 2016) (the quality/stability of the dispersion). But a global assessment could also be done by measuring the residual floating oil left on the surface (undispersed oil) at the end of the test (Baszanowska et al. 2019; Duan et al. 2019).

Mesoscale tests may be expensive and messy, but when they are done carefully, they can bring greater realism compared to laboratory bench-scale tests (National Academies of Sciences and Medicine 2005). Because of its large scale, mesoscale experiments are considered to be more representative of the real sea conditions. Mesoscale testing can be used to tie the artificialities of laboratory studies to the operational realities of dispersant use in spill response. As such, mesoscale testing should be judged primarily on the basis of the additional realism-over laboratory studies-that is incorporated into their test design while remaining sufficient controls to allow the replication and the collection of quantitative data (National Academies of Sciences and Medicine 2005).

Different types of mesoscale test tanks have been designed around the world; they have been used to investigate the chemical dispersion in the context of surface oil/ surface dispersant application. The main types of mesoscale testing facilities include the straight flume tanks (linear canals), the circulating flume tanks (loop canals) and the testing pools. There is an additional type of mesoscale testing facility which can be deployed at sea or in a large natural water body, the floating cells. Each facility has its advantages and disadvantages and is more adapted/efficient to carry out certain investigations than others.

\section{The straight flume tanks}

The straight flume tanks are linear canals (or straight canals) around 10 to $30 \mathrm{~m}$ long, 0.5 to $1.2 \mathrm{~m}$ wide (relatively narrow), and 1 to $2 \mathrm{~m}$ deep. The water capacity of these mesoscale facilities is typically around 10 to 20 $\mathrm{m}^{3}$. They can be indoors or outdoors for the larger ones. They are equipped with a wave generator. To get a wellcontrolled wave agitation, the wave generator at one end of the canal may be designed to generate specific waves (specific frequency and height) while the other end of the canal is equipped with a device for avoiding wave reflection (waves damper). In these wave tanks, by modulating the wave generated at one end of the canal, it is possible to get repeatable breaking waves at specific spots of the canal (Li et al. 2017).

At the beginning of a test, the oil is released and kept confined at a specific spot of the canal, then treated before the containment is removed and agitation is started; the dispersion process starts and can be monitored. If the canal is equipped with a flow-through system, the dispersed plume is progressively moved forward with the water. The dispersant is added by a regular sprayer which allows a realistic contact condition between the dispersant and the oil, but a part of the sprayed dispersant may be lost aside the oil slick and on the walls of the tank, which may lead to the uncertainty of dispersant to oil ratio (DOR).

These facilities are suitable to carry out dispersion with a controlled and repeatable mixing energy level. A few studies have been conducted to quantify the level of mixing energy provided by those facilities (Venosa et al. 2005; $\mathrm{Li}$ et al. 2017). However, its comparison with real sea states is difficult and empirical as the quantification of the level of mixing energy at sea remains uncertain concerns, especially at the local scale. However, wave tanks are closed systems (except it is equipped with a flow-through system), which have the limitation on fully reproducing the open sea environment. Their limited dilution capacity may lead to enhanced coalescence of dispersed oil droplets. Limiting the oil quantities used for the tests is a way to counteract this problem (i.e., keeping the oil amount negligible compared to the volume of water). It is worth mentioning that these facilities are not suitable for oil weathering. If necessary, weathered oil needs to be prepared and weathered separately. This can be done artificially in the laboratory or in another tank, in which the oil is let to evaporate and emulsify naturally. Also, due to the narrowness of the strait flume tanks, some oil can be trapped on the walls of the tank, particularly when testing sticky oils (weathered emulsified oil), which may skew the test itself.

There are several straight flume tanks in the world, but usually, it is not allowed to release oil inside as they are devoted to hydrodynamic issues. DFO Canada and S.L. Ross operate specialized wave tanks devoted to oil pollution issues. Additionally, there are straight canals that are not equipped with wave generators. In the context of oil spill response, they can be used for studying sub-sea release, or completing ecotoxicity experiments.

Testing pools are generally large water bodies designed to implement testing activities. These are often equipped with a large wave generator designed to produce well controlled surface mixing (round and breaking waves). Sometimes they can be equipped with a specific feature 
to generate a controlled stream of water. When placed indoors, experiments can be performed with temperature control (such as in Norway, -SFT or Sintef). However, a lot of these facilities are devoted to studies other scientific activities (i.e., hydrodynamics) and oil release inside is not allowed. Those which are designed for oil pollution activities are not necessarily opened to testing dispersion. One reason is that dispersion tests would produce large volumes of polluted water that would have to be filtered/ cleaned before disposal.

The testing pools are appropriate to investigate the actual relationship between dispersant penetration and oil characteristics because these systems are large enough to use realistic dispersant application systems (e.g., spray booms with typical nozzles) and they can be designed well enough to characterize the fraction of dispersant droplets that encounter floating oil (National Academies of Sciences \& Medicine 2005).

The largest testing pool is the Ohmsett facility (Oil and Hazardous Materials Simulated Environmental Test Tank), which was originally designed for testing mechanical oil recovery equipment. Now, it has been adapted with a filtration system to implement testing with dispersed oil. This facility is more than $200 \mathrm{~m}$ long and equipped with movable bridges which can browse the pool at a controlled speed. The pool contains nearly $10,000 \mathrm{~m}^{3}$ of water, which can be chilled if necessary.

A test usually involves releasing oil into an area $(\approx 900$ $\mathrm{m}^{2}$ ) surrounded by a floating boom. Then the wave generator is activated to complete the dispersion process. The entire volume of the tank is available for the dilution of the dispersed oil plume. The dispersion can be monitored through oil concentration and mean droplet diameter measurements. Confining the oil in an area allows weathering the oil in natural conditions ahead of the dispersant test, and it offers the advantage to better target the slick when applying the dispersant. Conversely, confining the slick presents the inconvenience of biasing the oil natural spreading, and according to the wind, the oil distribution in the confining device may be heterogeneous (oil accumulates downwind). In order to avoid these inconveniences, another way to proceed is using the movable bridge at a controlled speed to spill the oil and to treat it in the same run, in such a case the slick is no longer confined. The large size of the Ohmsett pool offers the possibility of investigating certain aspects of operational effectiveness (e.g., the dispersant application equipment can produce dispersant droplets with realistic size distributions) and hydrodynamic effectiveness (e.g., the facility allows dispersed oil to diffuse in a relatively large volume of water). It also allows effective studies under specialized conditions (e.g., in broken ice). The huge-sized pool provided by Ohmsett best simulates the real marine environment and thus allows for the full-scale validation of laboratory work, especially the laboratory testing methods (Holder et al. 2015; Ross 2013). However, the large size of the tank also presents several difficulties. The primary one is the high operational cost (e.g., the cost of chilling $9700 \mathrm{~m}^{3}$ of seawater is considerable). This financial constraint may lead to the lack of sufficient replication of the experimental designs to support the statistical analysis of the results. In addition, once the oil is released, the slick could rapidly drift from one side of the tank to the other, particularly with strong wind. Therefore, the dispersants need to be immediately applied after the oil release in the mesoscale test. In addition, the tank is too large to allow the water to be replaced after each test to avoid possible biases caused by residual oil and/or dispersant on the following tests. The maximum dispersant concentration that can be present in the water without affecting the validity of subsequent effectiveness tests is $400 \mathrm{ppm}$, and to date, this concentration has not been exceeded in sequential tests (Ross 2013). However, the 400 ppm oil concentration considered by the operators represents one, possibly two, orders of magnitude the actual concentration measured at sea. It is doubtful such a high concentration could not bring perturbation by promoting oil droplets coalescence. The presence of dispersant may lead to a more acute problem disturbing the oil spreading (Gomaa 2013; Nedwed et al. 2011).

Many studies have been conducted in straight flume tanks in the recent five years. At the Ohmsett facility, Steffek et al. (2017) conducted large-scale comparative testing regarding the effectiveness of five different dispersants and found that Finasol and Corexit have the best performance. Boufadel et al. (2017) studied the chemical properties of the Ohmsett tank water and found that the hardness of water was below the value in oceans, it could enhance oil dispersion compared with in oceans. Brandvik et al. (2021) investigated oil droplet size distribution under various conditions, they generated an extensive data set on oil droplet sizes from subsea releases and found that the data set could well fit modified Weber scaling for predicting oil droplet sizes. Zhao et al. (2016) conducted a large-scale experiment of underwater oil release at Ohmsett, and measured the plume trajectory, velocity, oil droplet size distribution, and oil holdup during underwater oil release to validating the models JETLAG and VDROP-J. In addition, Fisheries and Oceans Canada (DFO) Centre for Offshore Oil, Gas and Energy Research (COOGER) wave tank was well used in different studies. King et al. (2018) studied the DE of four oil products by natural and chemical dispersion in different seasons and found the dispersant increased the DE by order of magnitude compared with natural dispersion 
and the DE of dilbit was highly dependent on the season. O'Laughlin et al. (2017) explored the formation of dilbitderived oil-mineral aggregates (OMAs) in COOGER wave tank, and they found that in cold water $\left(<10{ }^{\circ} \mathrm{C}\right)$ and at a low sediment concentration, the in-situ formation of OMAs in the wave tank was unsuccessful. Zhao et al. (2017) adopted a horizontal release of oil without and with dispersant at COOGER wave tank and developed a new conceptual module VDROP-J to capture the tip streaming observed.

\section{The circulating flume tanks}

The circulating flumes form loop canals. Usually, their total length is approximately $10 \mathrm{~m}$ for a volume of 5 to $10 \mathrm{~m}^{3}$, in which the water is circulated during the duration of the test. These canals are designed to recreate sea conditions. Generally, they are located in a temperaturecontrolled room, and equipped with a wave generator, a fan to recreate the wind, and a ultraviolet (UV) lamp to mimic sunlight (Fig. 1). This facility allows oil weathering in realistic conditions, which involves all the different phenomena (evaporation, emulsification, photo-oxidation, dispersion) simultaneously (Delacroix et al. 2016).

The circulating flumes are mainly used to assess the dispersibility of oils according to its weathering stage. These are used to determine the possible place (role) of the chemical dispersion when implementing oil spill contingency plan; forecast the evolution of an oil and to test the different combatting techniques; and assess alternative combatting techniques regarding specific oil in specific environments. Accordingly, there are two ways to process the tests. For the first one, the oil is weathered gradually and turn in the loop under the waves and the wind. When the oil is sufficiently weathered, the dispersant is applied on the oil and then the dispersion of the oil can be observed and monitored. Such tests could estimate oil dispersibility at a certain weathering degree. The second one, the oil is weathered gradually in the tank, and oil samples are collected, characterized and tested regularly in bench scale to assess their dispersibility. The changes of oil dispersibility with its viscosity evolution can be determined and the feasibility of dispersant application thus could be predicted. The advantage of the circulating flumes is the possibility to study the whole evolution of oil, including the weathering process, especially when performing aside the measures on oil samples taken in the flume tank. When dispersing the oil directly in the loop tank, the plume of dispersed oil can be monitored while it turns in the loop and progressively dilutes into the whole volume of the loop. At the end of such a test, an oil balance sheet can be performed between the dispersed and non-dispersed oil fractions. The dispersant can be applied in a realistic way (using a sprayer), but, as in wave tanks, some dispersant can be lost in the water or on the flume tank walls. All characteristics of a specific environment can be recreated and well controlled

\section{Characteristics}

- Made of $4 \mathrm{~mm}$ stainless steel

- Length: $12 \mathrm{~m}$ Height: $1.4 \mathrm{~m}$ Width: $0.6 \mathrm{~m}$

- Air conditioned room $\left(1-30^{\circ} \mathrm{C}\right)$

- Water volume: $7 \mathrm{~m}^{3}$ for a water depth of $90 \mathrm{~cm}$

- Wave generator with adjustable wave height, amplitude and frequency

- Simulation of solar radiation by two $2000 \mathrm{~W}$ units which recreate the spectrum of natural light

- Air flow at the water surface simulated by a wind generator

- Removable covers and vapour extraction

- Variable speed current generation

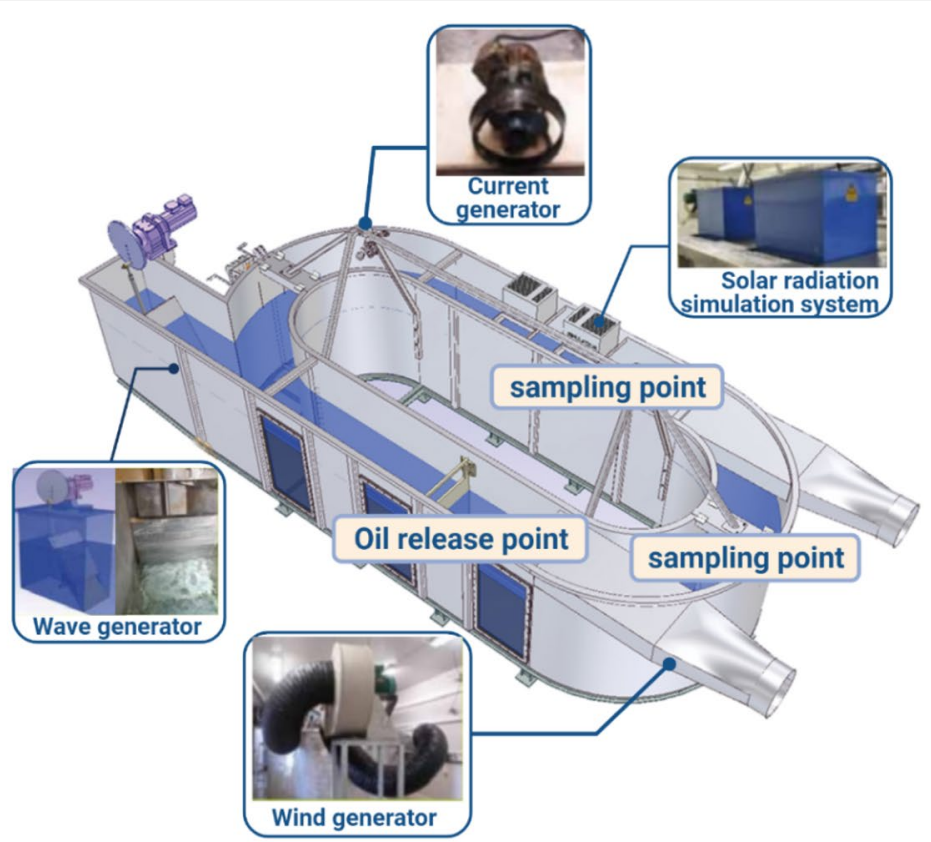

Fig. 1 Main feature of Cedre's circulating flume. The components include stream generator, solar radiation generator, wave generator, and wind generator (Cedre 2014) 
(i.e., agitation, wind, solar exposition). The level of mixing energy can be adjusted in the tank (easily by adjusting the frequency of the wave beater). However, the experimental conditions created in the wave tanks still cannot represent the real marine environment. Moreover, the agitation created in the circulating flume tank is less controlled than the ones in the straight wave tanks, thanks to the overlapped waves generated in the loop. In addition, as the pollutant circulates in the loop during the test, it regularly passes the vicinity of the wave generator. In addition, care should be taken to avoid the close even direct contact with wave generator, through which a high agitation could be created and adversely affect the oil behaviours.

Although field tanks mimic the environmental conditions of the sea, the weathering processes at sea and in a canal may differ. Test tools designed to simulate sea conditions manage to reproduce the extent of oil weathering processes and the oil dispersibility but fail to reproduce the kinetics of these changes. Therefore, at sea trials remain essential for the development of predictive models, particularly to clarify evolutionary kinetics. Till now, there are four flume tanks located in Sintef-Norway, Cedre-France (Polludrome), S.L. Ross-Canada, and Environment Canada. After the construction of SINTEF flume tank in Norway $(0.5 \mathrm{~m} \times 0.4 \mathrm{~m} \times 4 \mathrm{~m} \mathrm{~W} \times \mathrm{H} \times \mathrm{L}$, with $1.75 \mathrm{~m}^{3}$ of seawater), a set of other flume tanks have been developed, on the grounds of the design presented by SINTEF. The Polludrome flume tank was developed by Cedre-France had a much larger size $(0.6 \mathrm{~m} \times 1.4 \mathrm{~m} \times 1$ $2 \mathrm{~m} \mathrm{~W} \times \mathrm{H} \times \mathrm{L}$, with $10.5 \mathrm{~m}^{3}$ of seawater). A large storage tank was equipped with the tank, allowing the pumping of water and generation of tides. Instead of using UV lamps in SINTEF tank to simulate the photooxidation process, Polludrome adopts a solar radiation simulation system for such a process. Also, a laser particle size analyzer was equipped for Polludrome to evaluate the oil droplet size distributions. The flume tanks at S.L. RossCanada and Environment Canada were developed based on the existing flume tanks located at Sintef-Norway and Cedre-France. It worth mentioning, the tank constructed by Environment and Climate Change Canada is intended for long term evaluation of chemical spills in aquatic environments (freshwater and marine environment) under temperate and Arctic conditions (National Academies of Sciences and Medicine 2020).

Several studies have been conducted in circulating flume tanks recently. Faksness et al. (2017) summarized results of approximately 70 tests performed in the recirculating flumes at Sintef and S.L. Ross, they found that the oil dispersant effectiveness varied with both oil and dispersant type, and dispersants could be considered as a response option for spills in ice. Jézéquel et al. (2018) assessed the ability of clays to create oil-mineral aggregates and dispersed oil under arctic conditions in Cedre's flume tank and found that high mixing energy was required to initiate OMA formation and low energy was necessary to prevent the OMAs from resurfacing. Guyomarch et al. (2012) simulated various oil weathering processes in the Cedre's circulating flume then measured different parameters including density, viscosity, chemical composition, flash point, chemical dispersibility, etc. Cyr et al. (2019) tested the applicability of an ocean glidercompatible fluorescence sensor in Cedre's circulating flume, it suggested that the calibration on Water Accommodated Fraction (WAF) of crude oil is more appropriate than on pure standards as the concentration based on the WAF calibration was close to gas chromatography-mass spectrometry (GC-MS) results. In several laboratories (e.g., Sintef and Cedre), the circulating flume tanks are regularly used to document oils in production about their behavior and dispersibility in view to define and optimize the most appropriate emergency plans.

\section{The floating cells}

The problem inherent with the previous mesoscale testing methods is the difficulty in characterizing the level of mixing energy in the testing facility in relation to a sea state. The floating cell therefore, is an alternative to overcome such difficulty. Floating cells are floating flexible enclosures moored in the real marine environment, in which experiments can be performed. These experiments benefit from real marine conditions, wind, temperature, but also natural waves. A floating cell is composed of a frame $(3 \mathrm{~m} \times 3 \mathrm{~m})$ with floats hanging a vertical flexible plastic forming a curtain few meters height $(0.8 \mathrm{~m}$ in the air and around 2 to $3 \mathrm{~m}$ in the water) (Fig. 2). As the curtain is flexible, it keeps "transparent" to the waves which can pass through with almost no perturbations: the agitation in the floating cells is the same as outside. To keep the curtain close to vertical, the curtain is weighted at its bottom. The bottom of the floating cells is open to the water column to let the natural dilution happens; the surface oil is contained by the curtain while the dispersed oil and soluble compounds can dilute almost naturally. In the meantime, the frame offers an easy path for the operator to move and work all around. Several floating cells can be operated simultaneously.

Floating cells benefit from true natural conditions. Therefore, there are adapted to weather the oil (true evaporation, emulsification, and photo-oxidation). They have been used to study the fate and behaviour of oil and chemical dispersant when spilled at sea, and to assess the combatting techniques, particularly the dispersion of oils weathered to various degrees. In order to link the observations to the very local conditions (wind, sun, 


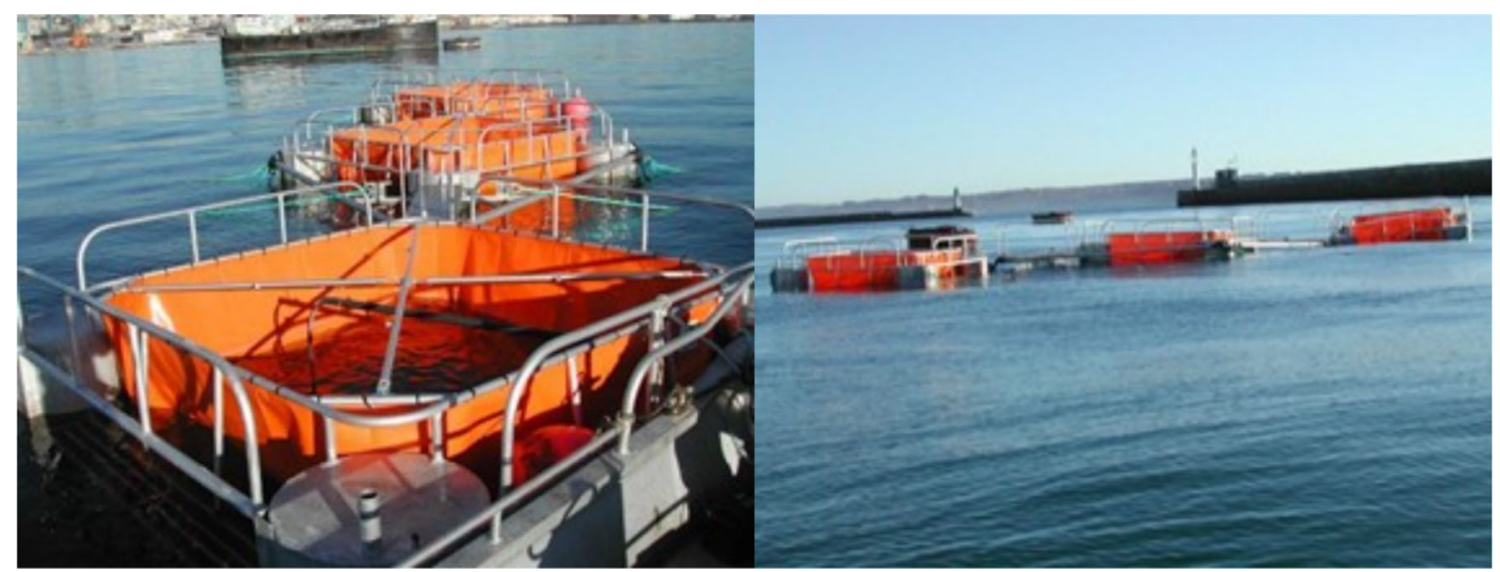

Fig. 2 Current floating cells moored in the entrance of Brest military harbour

temperature, etc.), a weather monitoring station has been set on a floating cell.

Cedre (France) used to run up to 6 floating cells, which opens the possibility to complete comparisons of several treatment products, to assess a treatment product according to different weathering stages, or to run comparative studies between different oils. The configuration and/or design of floating cells can be adapted to different objectives, such as OMA formation studies and sorbent testing, etc.

However, the floating cells have some limitations. As all the other mesoscale testing facilities, the spreading of the oil (or any floating pollutant) is limited by containment. Besides, as observed in the Ohmsett facility, the wind may prevent the oil from distributing evenly in the cells (the oil is often pushed to one side). Also, as to any outdoor facility, the operators must deal with the existing ambient conditions. The oil slicks attached to the curtains (especially for long-term experiments) could add a bias as well. Running the floating cells requires logistics support (e.g., a small boat), an authorized mooring location, the permit to run experimentation in an open environment, although the testing oil quantity (few litres) are very limited and the possible losses of oil are only nonpersistent oil like dispersed oil or dissolved compounds (the persistent oil or emulsion is kept confined).

\section{High pressure testing tanks}

In 2015, the hyperbaric chamber of the SwRI (Southwest Research Institute, San Antonio TX) was used by Sintef to run a series of experiments on sub-sea dispersion using oil and natural gas. The purpose of these experiments was to check if pressure could change the subsea dispersants injection (SSDI) effectiveness as previously assessed in tests completed at ambient pressure (atmospheric) (Brandvik et al. 2016). The SwRI hyperbaric chamber is exceptionally large, with a diameter of $2.3 \mathrm{~m}$ and a height of $5.6 \mathrm{~m}$ (volume of $24 \mathrm{~m}^{3}$ ). Its rated pressure is 275 Bars (simulated pressure $\approx 2700 \mathrm{~m}$ ). Oseberg crude oil was treated with 1 and $2 \%$ dispersant at different pressures $(60,120$ and 170 Bars) and natural gas was added from time to time. The oil was either dead oil, or simulated lived oil obtained by spraying dead oil in a pressurized tank filled with natural gas in order to reach between 10 and $90 \%$ vol at testing pressure. The oil and gas effluent with or without dispersant were injected through a nozzle in the chamber filled with sea water and the rising oil plume was monitored using the Sintef's SilCam (Fig. 3).

These studies indicated that SSDI effectiveness did not seem to depend on pressure (water depth) or the presence of gas provided one accounts for the effect of gas on the exit velocity. Also, gas bubble size could be significantly reduced due to dispersant injection. However, it must be noted that the investigated gas to oil ratio (GOR) range in this experiment does not cover all situations that can be encountered in oil fields. In addition, this experiment only investigated the formation of oil droplet, without further looking into the stability of the dispersion with time. At last, due to the risk of hydrate formation, conversely as planned, tests at low temperatures had to be canceled to keep over the domain of formation of hydrates. Certain water and oil samples taken from the chamber formed stable w/o emulsion during the progressive decompression before further analysis in the laboratory (the measurement of the inter facial tension). Due to the difficulties of carrying out tests under high pressure, most of the mesoscale experimental work was done at ambient pressure using vertical tanks (water column) or straight hydraulic canals. 

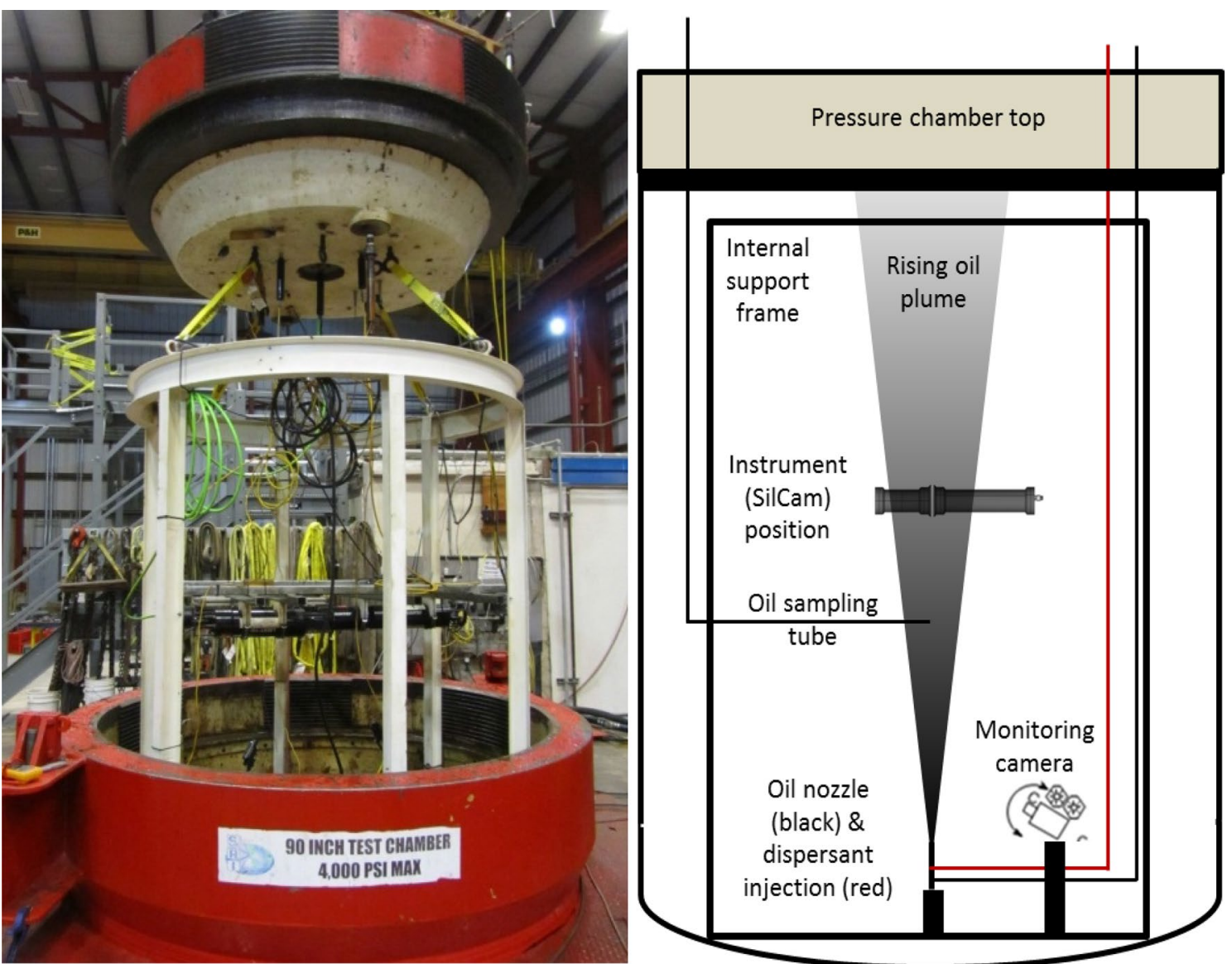

Fig. 3 Pressure chamber for oil spill tests. Top left: Pressure chamber open and ready for insertion of the monitoring frame with the SilCam. Top right: Schematics of the experimental set-up (Brandvik et al. 2019c)

Studies have been conducted under high pressure to explore its influence on oil droplet size and dispersion effectiveness. The droplet size formed by the live oil and gas under high pressure was investigated by Brandvik et al. (2019b) at SINTEF and SwRI. Their study indicated that the oil droplet size was independent of pressure, but negatively correlated with the gas void fraction. This result was also confirmed by Song et al. (2021), whose team reported insignificant difference on pre-dispersed oil droplet size distribution under high pressures (up to 150 bar). Brandvik et al. (2019c) further quantified the oil droplet size released from an orifice in seawater at low and high pressure (5 $\mathrm{m}$ and $1750 \mathrm{~m}$ depth), whose results also indicated the limited impact of on oil droplet sizes. Malone et al. (2018) investigated the influence of high hydrostatic pressure (150 Bars) and dissolved gases on the droplet size distribution, results showed that methane dissolved in the liquid oil increases the volume median droplet diameter significantly by up to $97 \%$. Pesch et al. (2018) studied the rise velocity of live oil droplets under high pressure and validated the model using for the rise velocity calculation of oil droplets.

\section{Large water column testing tanks}

Vertical tanks have been used to study the oil behaviour in underwater for a long time. Cedre used a transparent mini column ( $0.3 \mathrm{~m}$ diameter for $3 \mathrm{~m}$ height) to observe and study the sedimentation behaviour of partially soluble chemicals in seawater. Based on this experience, Cedre further built a much larger column tank (hexagonal, $0.8 \mathrm{~m}$ width and $5 \mathrm{~m}$ height) equipped with large windows to study the behavior of contaminants, mostly with density lower than that of seawaters (Even 2003) and dispersed oil droplets. It has been possible to visualize the strange behavior of dispersed oil droplets, such as became elongated under the friction of the surrounding water during their ascent, form long tails, and seed tiny droplets behind then (Fig. 4) (National Academies of Sciences and Medicine 2020; Vanganse 2013). The equipment includes optical cameras for pictures that can be analysed afterward. In addition, the tank is equipped 


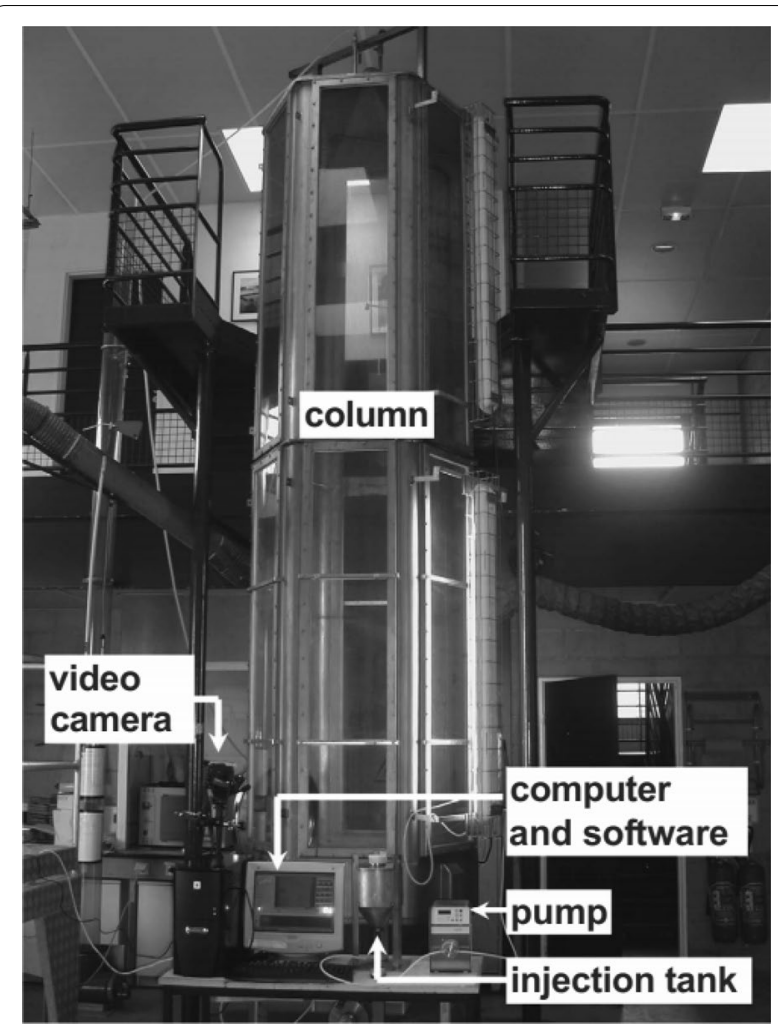

Fig. 4 Column testing tanks for the oil behaviours in the water column. Left: Cedre tests column: a hexagonal $5 \mathrm{~m}$ height and $0.8 \mathrm{~m}$ wide featured with 4 large windows dedicated to the study of the behavior of pollutant in the water column. Right as an example of work carried out in Cedre's tests column, picture oil droplets treated with dispersant rising up towards the surface, stretched vertically by the friction with the ambient water and loosing tiny oil droplets during their ascent (Stéphane et al. 2009)

with outlets vertically dispatched every metre for sample collection. For safety reason, the tank has an outlet to extract any eventual harmful vapor.

Similarly, in 2005, Sintef built a much larger vertical tank, the "Tower Basin" (3 m diameter, $6 \mathrm{~m}$ height, 40 $\mathrm{m}^{3}$ sea water) (Fig. 5). This facility was used to study the underwater oil plume formation treated with and without dispersant. To simulate more realistically blowout conditions, the facility is designed to release oil and gas (air but possibly natural gas) and/or water at a desired pressure and temperature, with a known quantity. In addition, dispersant can be injected into the upstream and/or downstream of the oil release point (nozzle), in known quantity to achieve a specific DOR.

A lot of instruments are installed in the Tower Basin to monitor the dispersed plume up to three meters above the release point: the droplet size distribution of the dispersed oil is monitored using video cameras (3 to 6 cameras), particle size analyser (LISST 100X), particle visual microscope (PVM) and macro camera/laser; and an in-situ UV Fluorometer can be used to monitor the oil content/dissolved components in the water. There is possibility to take oil and water samples from the facility as well.

This facility was designed to study the behaviour of oil released into the water column under high pressure (i.e., with sufficient shear rate) and variable dispersant additions to promote oil dispersion. The main parameter used to assess the dispersant effectiveness is the changes in the size distribution of oil-droplets with and without dispersants. Usually, an efficiency test of a dispersant evaluates the evolution of the oil droplet sizes with the progressive increase of dispersants dosage (in steps every 0.5 to $2 \mathrm{~min}$ ). The Tower Basin is a closed system and the oil concentration in the water can be gradually increases during the tests. Therefore, it is necessary to limit the number of consecutive tests and to settle, clean, and filter the water every night to reduce oil accumulation and avoid water changes with tank cleaning.

Several studies have been conducted at the Sintef Tower Basin and Cedre Experimental Column. Brandvik et al. (2017a) performed up-scaled experiments at the Sintef Tower Basin and generated new data set to test the modified Weber Equation's ability to predict initial droplet sizes. Results showed that the experimental data could highly fit predicted values from the modified Weber algorithm. Brandvik et al. (2018) compared the effectiveness of different dispersant injection techniques for subsea dispersants injection, they found that smallest droplets could be observed when dispersant was injected immediately before or after the release opening. Brandvik et al. (2019a) proposed an expression for interfacial tension (oil-water) as a function of dispersant dosage based on the data regarding the relationship between dispersant dosage and interfacial tension obtained from experiments at Sintef Tower Basin. Aprin et al. (2016) simulated the chemical discharge experiments in the Cedre Experimental Column, they measured mass flow rate and draining time, then proposed a model based on Reynolds number power law to characterize the discharge coefficient. Table 1 compares the properties, advantages and disadvantages of different tanks.

\section{Marine oil dispersion field trials}

Tough the laboratory and mesoscale studies attempt to create sea conditions in their tests, this objective cannot be fully achieved. The agitation generated by the test facilities cannot fully represent the real wave conditions. Further, the closed environment (i.e., flask and tank) generates wall effects and limits the potential oil spreading at the surface and oil dilution/dispersion in the water column. These conditions are of great importance when studying the dispersion technique that requires agitation 

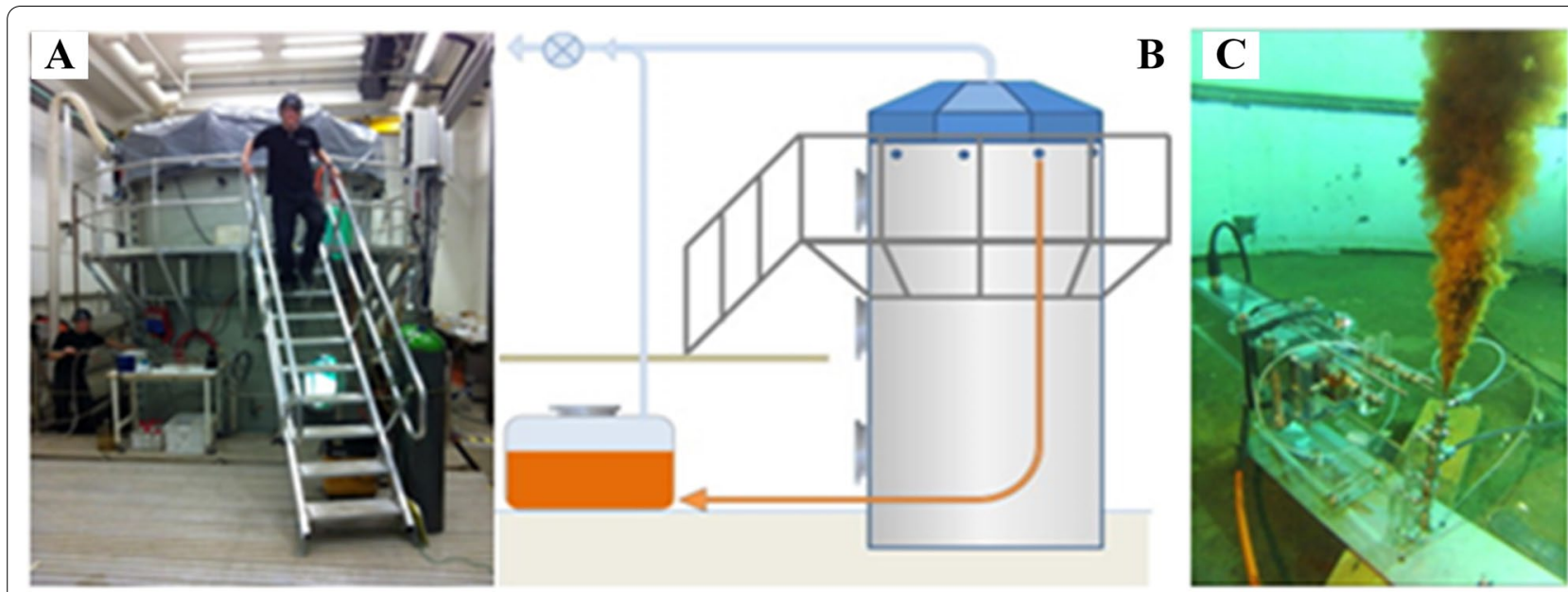

D

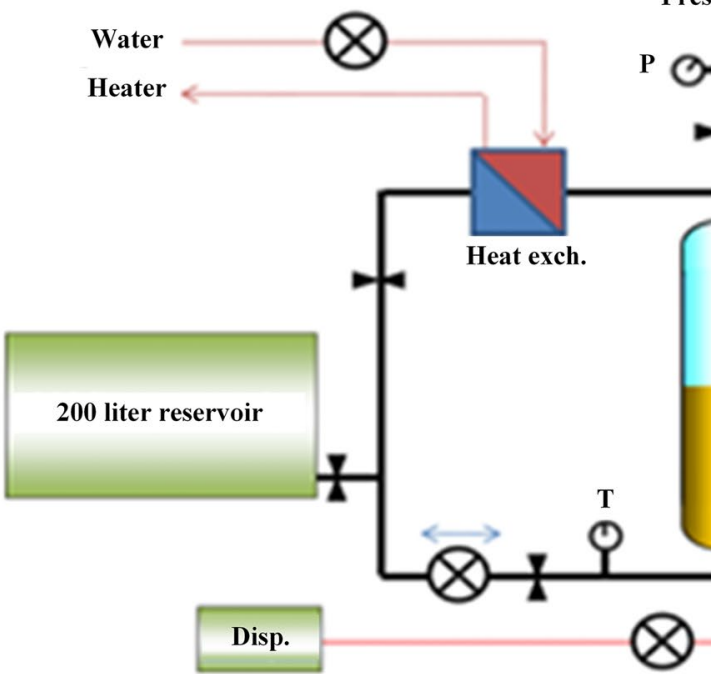

Fig. 5 The tower basin for oil pill test. A the tower basin facility showing the ventilated hood, scaffolding, staircase, and the railings to ensure safe working conditions (Brandvik et al. 2013); B principles for the scaffolding/railing around the tower, ventilated hood and overflow system to collect surface oil from the top of the tower (Brandvik et al. 2013); C view of the oil injection system at the bottom of the Tower Basin (Brandvik et al. 2013); D Principle overview of the set-up showing how oil, gas and dispersant are released during the experiments (Brandvik et al. 2014)

and diffusion/dilution. Field trials at open sea thus were conducted to overcome the above-mentioned limitations and bring greater realism into the assessment. Since the 1980s, many sea trials have been conducted in several countries, particularly in Europe and North America (Faksness et al. 2016; Lewis and Prince 2018; National Academies of Sciences and Medicine 2020). These sea trials aim to investigate the behaviour of different spilled oils at sea and compare the operational effectiveness of oil spill response techniques (e.g., chemical dispersion, mechanical recovery, and in situ burning) in the real sea in a controlled oil release (e.g., the type and amount of the oil and the release method).

Despite the advantages offered by the field trails (e.g., realistic test conditions), those hard-to-control sea conditions also bring disadvantages. The operator needs to deal with the ambient conditions on the day of the experiment without change or modification. Regarding the chemical dispersion, the agitation conditions were too quiet (e.g., Depol 04 (Merlin et al. 2006)) or too bad (e.g., UK 2002 sea trials (Colcomb et al. 2005)) to fully achieve the original planned test program which had to be modified or postponed to a later date. Running an open sea experiment is more difficult than running a test in a testing facility designed for this purpose: the assessment of dispersion in the open sea is more uncertain than in a mesoscale facility. For example, at sea, it is almost impossible to perform a full oil budget evaluation at the end of the trial. Evaluations are generally carried out by sampling and local measures or by indirect techniques. 
Table 1 Comparison of the mesoscale testing facilities

\begin{tabular}{|c|c|c|}
\hline Test facilities & Advantages & Disadvantages \\
\hline Straight flume tanks & $\begin{array}{l}\text { Dispersion test under a controlled and repeatable mix- } \\
\text { ing energy level } \\
\text { Operational effectiveness tests (in some large-sized } \\
\text { tanks) }\end{array}$ & $\begin{array}{l}\text { High operational cost } \\
\text { Cannot perform in-situ weathering, } \\
\text { Have difficulty in waters replacement }\end{array}$ \\
\hline Circulating flume tanks & $\begin{array}{l}\text { Investigate the oil evolution under controlled environ- } \\
\text { mental conditions; } \\
\text { Test the dispersibility of weathered oils (i.e., evaporation, } \\
\text { emulsification, photo-oxidation, dispersion) at realistic } \\
\text { conditions }\end{array}$ & $\begin{array}{l}\text { Less controlled waves } \\
\text { Oil behaviors could be affected by close oil and wave } \\
\text { generator interaction }\end{array}$ \\
\hline Floating cells & $\begin{array}{l}\text { Evaluate the oil dispersibility in real sea state (i.e., tem- } \\
\text { perature, salinity, wind and current) } \\
\text { Assess the fate and behavior of oil and dispersant }\end{array}$ & $\begin{array}{l}\text { The release and distribution of oil could be affected by } \\
\text { the wind } \\
\text { The spreading of oil could be affected by its containment } \\
\text { Request logistics support and permit }\end{array}$ \\
\hline High-pressure tanks & $\begin{array}{l}\text { Evaluate the subsea dispersants injection (SSDI) effec- } \\
\text { tiveness under high pressure } \\
\text { Test SSDI effectiveness of "live oil" }\end{array}$ & $\begin{array}{l}\text { Can only reflect the initial stage of oil dispersion at deep } \\
\text { water } \\
\text { Size is limited }\end{array}$ \\
\hline Large water column testing tanks & $\begin{array}{l}\text { Evaluate/visualize the sedimentation behaviours of } \\
\text { spilled oil } \\
\text { Assess oil droplet and gas behavior at subsurface } \\
\text { Enables experiments with larger oil flow rates over } \\
\text { longer time spans }\end{array}$ & $\begin{array}{l}\text { Ambient pressure } \\
\text { The tank size limited the oils that can be released into the } \\
\text { tank, and challenges the scaling of oil droplet size data }\end{array}$ \\
\hline
\end{tabular}

In addition, the logistics are heavier than mesoscale tests at sea (e.g., needs of ships, aircraft, etc.), the experiments are more expensive. As a result, it becomes difficult to multiply the tests to obtain the replicas needed to statistically irreproachable results. The sea trials implementation requires authorizations for the release of oil into the natural environment. Unfortunately, the authorities are often reluctant to give such authorizations even in case of perfectly controlled spills, carried out by specialists who have the expertise to do it. Yet, these well-controlled experiments have never resulted in significant and/or permanent damage to the environment. On the contrary, only by confronting the reality on the field, the knowledge could advance, the control techniques could progress, and the improvements could occur. Experiments in natural environments make it possible to highlight problems and difficulties that do not appear in simulations. Sea trials also make it possible to assess the capacity of operational resources in real terms. Anyway, sea trials are needed to validate mesoscale test programs results. Lastly, in addition to these technical and scientific aspects, the experiments at sea constitute a good training for the personnel in charge of the response.

It is sometimes proposed to take advantage of real accidents (spill of opportunity) to conduct experiments on instead of releasing voluntary oil spills at sea. But these spills of opportunity cannot replace controlled planned experiments because, on the one hand, the appropriate test conditions are never met to carry out a valid experiment (e.g., no possibility to choose the type of oil), and at the times of a real spill, responders have other objectives than organizing experiments. Depending on the research objectives, following factors shall be considered in the experimental design for sea trials:

- The choice of the products, especially the oil.

- The slick size. The larger the oil releases, the fewer the tests; conversely, it may be possible to carry out larger series of tests when dealing with small, limited slicks. The slick size depends on the objective on the trials (e.g., assessment of the operational issues needs realistic large slicks while testing the efficacy of oil spill dispersants can be completed on small slicks).

- The oil release mode which determines the slick shape. There are different ways to release oil at sea according to what slick is desired (e.g., natural surface spreading, a well-controlled oil thickness, etc.).

- The dispersant application mode and dosage can be achieved either using a specific fitted device to get a well-controlled application in term of application rate, droplet size, the use of an operational application means (e.g., a dispersant spraying aircraft). Once more, this depends on the objective of the trials (e. g., looking for pure efficiency of dispersant brands or assessing the actual capability of operational application means).

- The methodology to assess the chemical dispersion: it can be done with local measurements-observations, such as monitoring the dispersed oil concentrations and oil droplet diameter in the water using UV and/or particle size counter, or it can be done 
more broadly by looking the oil remaining on the sea surface using remote sensing aircrafts.

Several objectives may be considered when planning sea trials provided that they are not conflicting. In this respect, it is advisable that the objectives are prioritized, in order to organize the trial according to the main objective and then, to consider what is left for the others. As an example, the experiment Depol 04 was devoted to the comparison between aircraft and ship dispersant applications (Merlin et al. 2006). However, some synergy could be found with other objectives particularly regarding the aerial remote sensing techniques: these trials could be used to calibrate the remote sensing aircraft of the European Union and to train their crews. Quite the contrary, the aircraft brought a lot of aerial pictures of the slicks which were useful to assess the treatment efficiency of the different dispersant application modes. Generally, there are two main categories of sea trials:

- Small scale sea experiments which involve very limited slicks (e.g., around 0.1 to $1 \mathrm{~m}^{3}$ ) and in which the testing conditions (oil thickness, dispersant application, and dosage) are highly controlled. These are more devoted to the assessment of intrinsic efficiency of dispersants in an open environment.

- Large realistic sea trials, which involve much larger oil quantities (few to several tens of $\mathrm{m}^{3}$ ). These are designed to realistically re-create the actual conditions of a dispersion operation at sea. The objective may be to study the oil weathering process and the dispersion process, but these trials are often devoted to the evaluation of the operational combatting equipment and/or the appropriateness of the operational procedures.

- In addition, there are specific experiments which can be conducted on land to assess the capabilities of application means, particularly the aerial spraying devices.

\section{Small scale sea experiments of surface release}

These experiments are as doing "laboratory work at sea". Such studies were conducted to evaluate the behaviour of spilled oils (i.e., drifting, spreading, and weathering) validate laboratory testing methods in the marine environment (Faksness et al. 2016), and to assess the dispersibility limits of various viscosity oils (Lewis 2005). When completing at sea experiment on small oil releases ("mini slicks"), the natural dissipation of the oil is usually quite short. Therefore, pre-weathered oil should be applied in the tests. Due to the sea surface agitation, the dispersion can only be observed/monitored for a relatively short time before its natural dissipation. In the test, the monitoring facilities equipped on board should be as small as possible to avoid disturbing the released slick (e.g., to monitor the slick for a small inflatable boat cruising at low speed). Usually, oils were released from a boat moving at a controlled speed to form a track with a known thickness and width. A known amount of dispersant with a designed DOR is then applied for the assessment of dispersant efficiency.

Several approaches are developed for small scale tests to ensure a controlled experimental conditions (especially to achieve the designed DOR). The first approach applies the oil and the dispersant from a slowly moving ship (or barge). Such operation makes sure the dispersant application pattern could conform with the oil track as close as possible. However, the variations of oil thickness and shape of the slick created by the ocean waves could affect the dispersant application (i.e., the amount the dispersants hit to the oil), bringing in errors. The second approach applies the oil and dispersant from two different boats sailing one behind the other (Fig. 6) (Fingas 2014). This methodology was used to validate the IFP laboratory test method and special care was taken to keep the best reproducibility between different tests: the tests were completed in a calm coastal water body. Thus, the mixing energy needed for the dispersion was supplied by a net of floating plastic chains which depended only on the ship speed. The spraying equipment for applying the dispersant was specially designed to produce the same spray characteristic whatever the dispersant flow rate (using multiple spay booms). A third boat followed the two first ones to measure the dispersed oil concentration in the subsurface water (continuous monitoring by UV spectrofluorimetry). To avoid any disturbance to the dispersed plume (from the bow wave or the propeller), the oil sampler was set fixed in the front of the bow of the third boat.

The main advantage of this methodology was to offer the open sea condition for the dilution of the dispersion process. However, regarding the agitation, the use of floating plastic chains remained quite artificial. The methodology was more adapted to coastal sheltered waters than to the real open ocean. Nevertheless, as the boat could not stay all the time perfectly in line, sometimes the dispersant spray pattern could not be always perfectly matching the oil track. Thus, some dispersant could be lost aside from time to time inducing small variations of the DOR.

The "corridor system" was another testing arrangement designed to avoid these inconveniences, especially to ensure the whole oil be treated evenly by the dispersant. The corridor was composed of two floating booms towed aside of a ship (but at some distance with a jib) and linked 


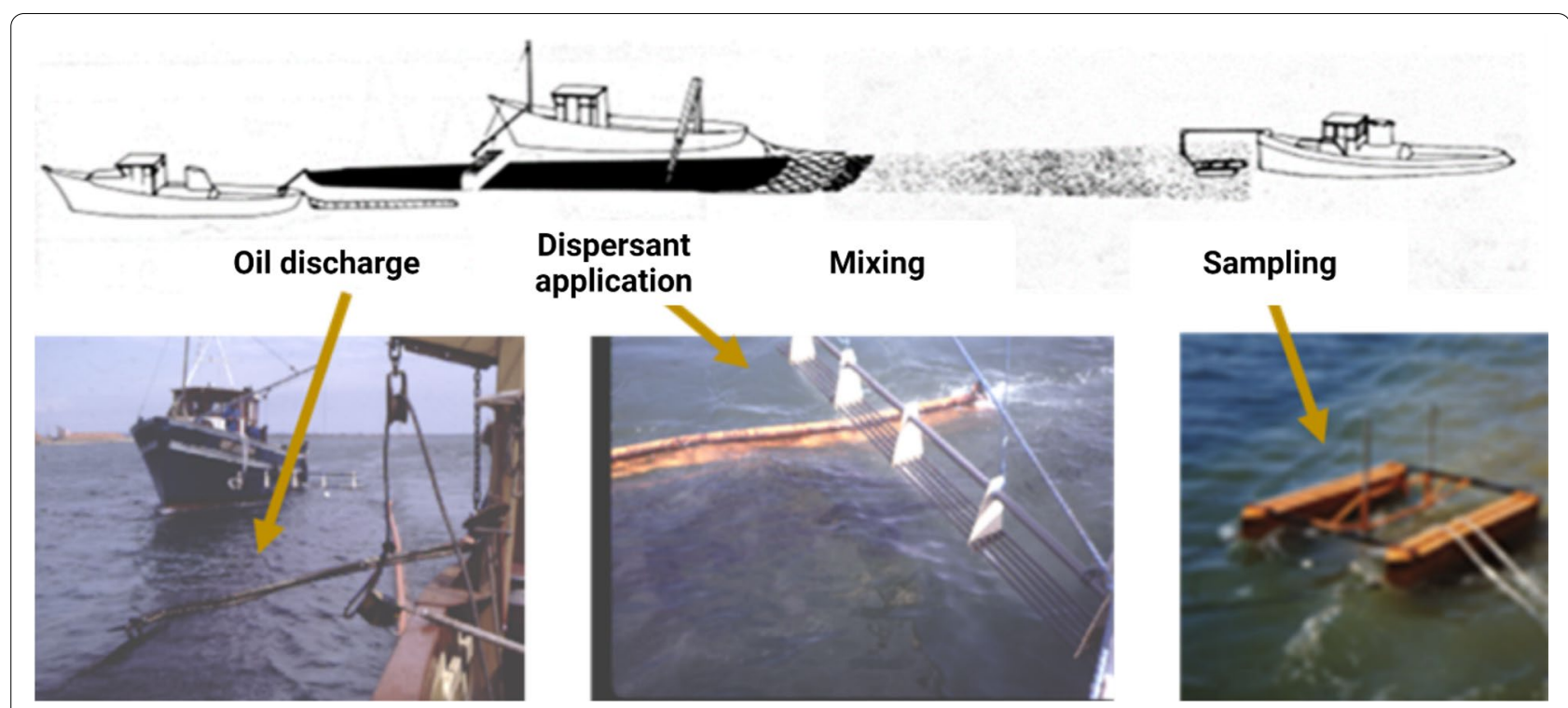

Fig. 6 Small scale sea test conducted in France. The first to apply the oil, the second to apply the dispersant and the third to measure the dispersed oil in the water column (Desmarquest et al. 1983)

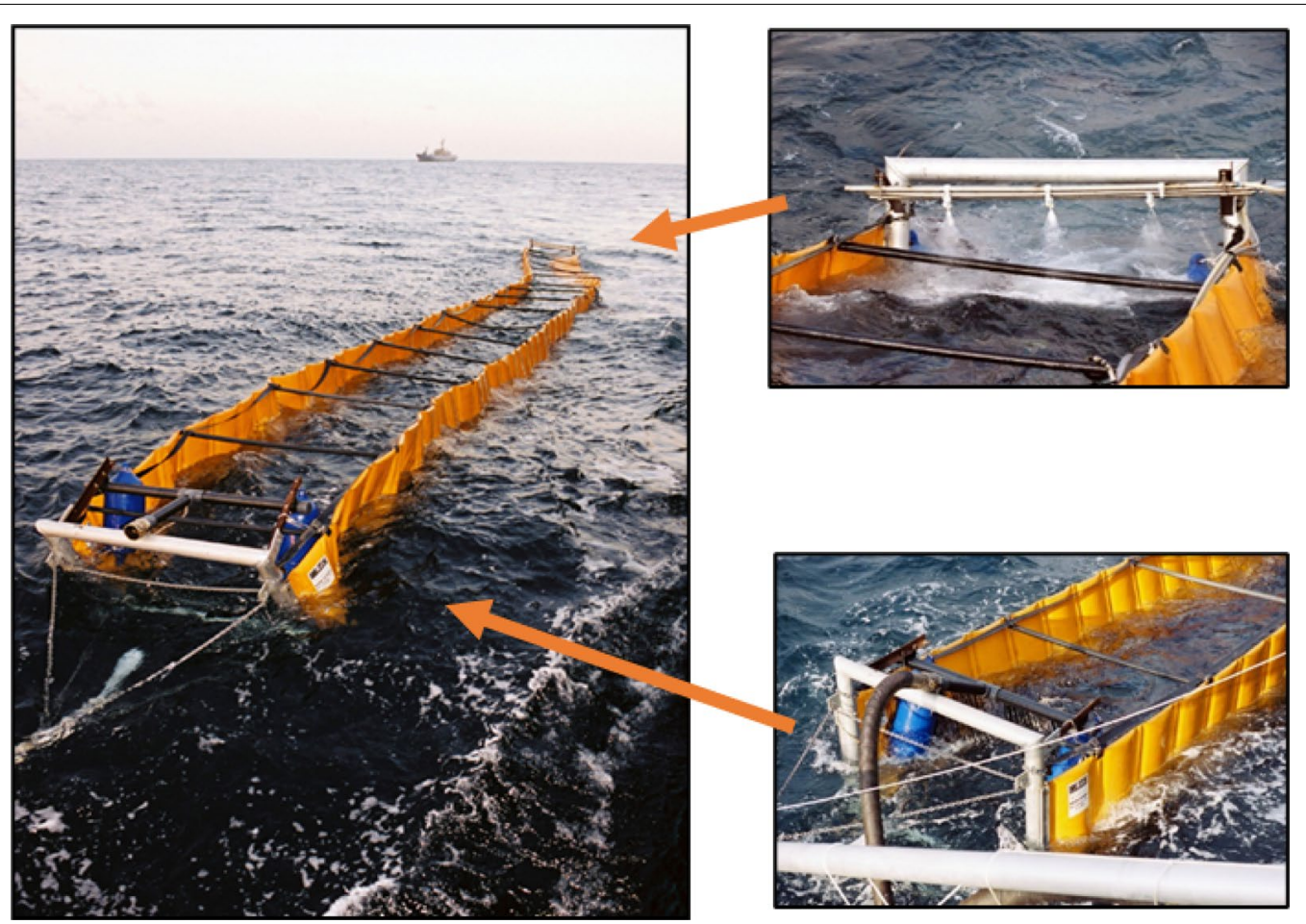

Fig. 7 The "corridor" system. Two parallel floating booms ended by frames, supporting the oil release arrangement at the entrance (bottom right) and the dispersant spray boom at the end (top right). This system has been implemented in 2005, during the French sea trials Depol05, which testing program has been unfortunately stopped prematurely due to a technical incident on the main ship. However, the corridor system proved to be promising: such testing procedure allows to run an important number of comparative tests with limited amount of oil. while working with highly controlled application conditions, especially regarding the DOR (Merlin 2008). 
at each end by a frame to form a floating corridor (Fig. 7). Each frame was fitted with a spray boom, one to apply a known quantity of oil and the entrance, and the other to apply the dispersant at the other end. Therefore, while the ship was moving slowly, the corridor was traversed through by a stream of water. The oil was released at the entrance and drifted gradually to the other end, which giving time to form an oil film. The oil film was treated entirely by the dispersant at the corridor exit. Then the treated oil left the corridor and dispersed in the open sea under the natural wave agitation. The dispersed oil could form a long plume which could be assessed using a small boat (e.g., inflatable) cruising through slowly to minimize any possible disturbance and/or by a panel of trained experts as previously. In order to facilitate the monitoring of such small oil slicks, the oil was released upwind so the slick kept a straight elongated shape. Buoys were launched at the beginning and the end of the oil release to mark out the slick/dispersed plume.

The last approach is a continuous release of oil. This sea test method used a vessel moored in a tidal stream to release oil which formed a long, continuous trail, behind the stern of the ship. The dispersion could be monitored on the water by a small boat following the oil trail and remotely by an aircraft equipped with infrared sensors. Taking advantage of a very steady steam field on their East coast, British researchers implemented this sea trial methodology to assess the chemical dispersion and its limits in the field (Fig. 8). Also, a results comparison has been made between the main laboratory testing methods and the field. This testing arrangement enables the performance of carrying out several tests in the same conditions (as long as the weather and the tidal stream keep steady). By performing transect across the oil track/plume, the dispersed oil proportion could be assessed by the sampling boat that monitored profiles of the dispersed oil in the water column and makes it possible to quantify the dispersed oil and assess the DE. By increasing the cruising distance from the moored ship, the dispersed oil plume could be evaluated for increased dispersion time (e.g., $30 \mathrm{~min}$ after treatment). It could be useful when the dispersion process is not immediate (e.g., when low agitation and/or limited dispersibility). Conversely, this testing method required larger logistics, such as a large ship to anchor in open sea and aerial surveillance with Infrared (IR) sensors to monitor the location of the boat. In addition, the continuous release led to a much larger quantity of oil released at sea than the other methods.

\section{Large scale sea trials of surface release}

Large sea trials release significant quantities of oil (possibly few tens of tons) to generate oil slick that could be generated by oil spills at sea. The slicks can be treated with dispersant (and possibly with other at sea combatting techniques) after few hours of weathering and with real operational combatting equipment. In this respect, the size of the slick should be appropriate to the size of the combatting equipment used. The heaviness and the cost of these sea trials are related to their size, and indeed to the size of the oil release. Large oil release requires larger (and more costly) combatting equipment, and test areas are increasingly far away from the coast for safety reasons (which may increase the cost too). In addition, for these trials, aerial surveillance is needed to track the oil. At last, for large sea trials, the combatting capability is usually increased in order to overcome the pollution in any case (e.g., for Depol 04 (Merlin 2008)).These large sea trials are usually designed for the evaluation of the fate and behaviour of oil at sea (oil weathering for several hours at sea) and what effect can be achieved by using actual equipment

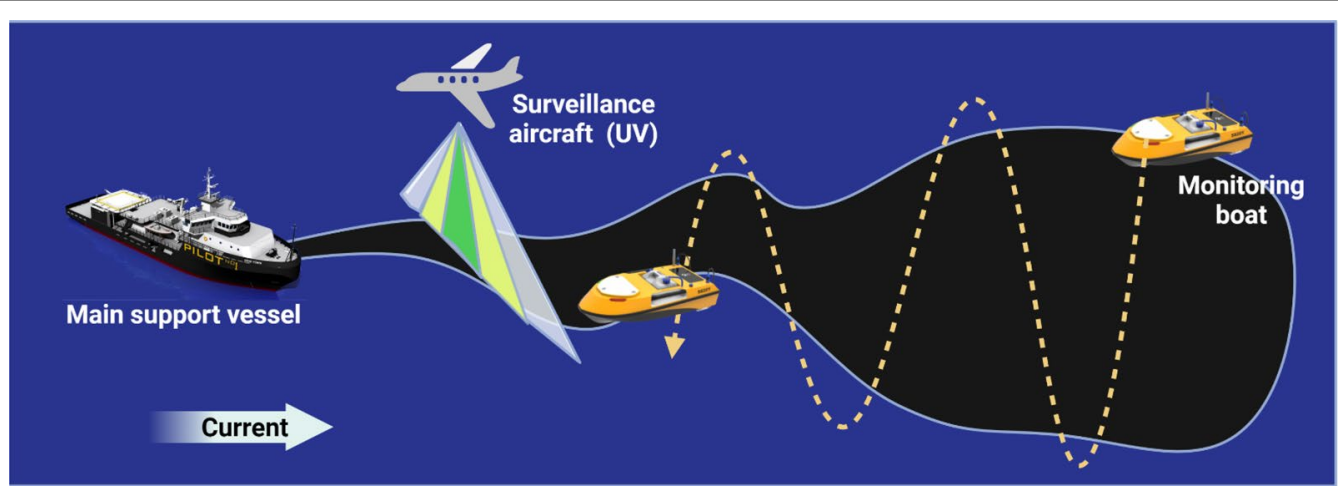

Fig. 8 A schematic diagram of the British test method. This method includes 1) the support vessel at anchor releasing and treating the oil in the tidal stream, 2) the sampling boat equipped with UV spectrofluorimetry, cruising through the oil trails and monitoring profiles of dispersed oil concentrations under the oil trail 
and procedures to implement dispersant on the realistically weathered oil. In addition, these sea trials are used to assess and/or to develop operational combating equipment, techniques (dispersion application equipment, remote sensing techniques etc.) or operating procedures.

The way to release the oil is crucial as the goal is to get a suitable oil slick for implementing the planned working program. According to the objectives of the experiment, the oil release may require a slick with specific characteristics in terms of extension, surface, oil thickness and possibly oil weathering stage. The wind determines the oil slick evolution (Fig. 9), but the way the oil has been initially released influences the final slick condition, especially if the time for oil weathering is short (few hours).

There are different ways to release oil at sea surface, such as the punctual spillage and the dynamic release (parallel to the wind or cross wind). For the punctual spillage, the oil is released as a "spot", which then could be spread naturally in all direction. This method tends to give a non-controlled/heterogeneous slick that has been used to study the behaviour of pollutant at sea under natural condition rather than the chemical dispersion. The dynamic release method on the other hand, release the oil from a ship cruising at low speed and enables the formation of evenly distributed oil slick on a large surface.

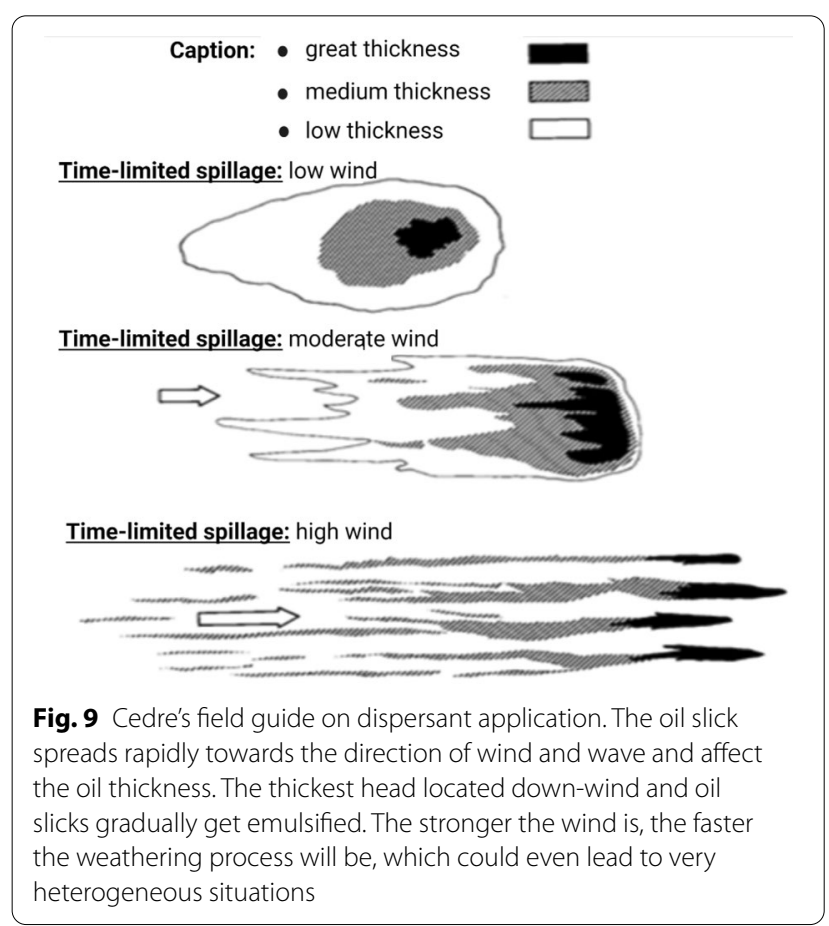

The following the assessment tools are widely used in dispersant field trials:

- Local measurements of the dispersion characteristics (oil concentration and oil droplet size), which can be punctual measurements or monitoring along a profile. This can be done by pumping continuously sea water at different depths which then can be analysed by appropriate measuring devices. Nowadays, in-situ analytical tools have been developed and applied in the field for a direct collection of field data. In addition, oil samples can also be collected for further laboratorial analysis to monitor the oil evolution as it weathers.

- Global assessment from the air (usually from aircraft). This assessment uses optical methods (e.g., UV, IR spectroscopy and visible domains), or more sophisticated devices (e.g., laser fluorosensor, microwave sensors, interferometric radars) for measurement (Fingas 2014). Information such as the location, extension of the slick, distribution of oil thickness, and oil quantity assessment can be obtained by these tools, especially when combining the information issued from different tools.

- In addition, temperature, wind, and waves are useful information that shall be determined in the field tests.

Through an understanding on the oil and dispersant properties, aerial imagery, local measurements, and dispersed oil samples analysed in the laboratory, field studies could provide an in-depth knowledge on the fate of the oil at sea including its drift, its distribution, its weathering (weathering kinetic) according to the prevailing ambient conditions; the evolution of the oil dispersibility according to its weathering degree; the global operational efficiency of the chemical dispersion, by assessing the residual volume of oil after treatment; and the capability of operational equipment such as dispersant application equipment.

Specific testing programs are devoted to the dispersant application equipment have been implemented in the context of sea trials. Laboratory studies and workshop discussion were conducted for equipment development (e.g., a nozzle) and operation condition optimization. Field tests were carried out to further evaluate dispersant application equipment for ships or aircraft. Most of these field tests were done in the frame of large sea trials. For example, Protecmar's sea trials between 1979 and 1986 helped develop a large helicopter sub-suspended spraying bucket (SOKAF 3000) (Daling et al. 2002). In addition, a large size shipborne application equipment with adjustable 
application rates was also developed (Merlin and Peigné et al. 2007). Similarly, the underslung helicopter based dispersant system "Response 3000", developed by the Norwegian, has been validated through the annual Norwegian sea trials (Faksness et al. 2016). More recently Norwegian sea trials helped to develop large shipborne spraying types of equipment, for open sea and for ice infested waters.

In addition to sea trials, the development of application equipment has also involved large on-land field trials to document the spraying characteristics of the application devices. These trials, which also concerned spraying aircraft, consisted in aircraft flying and spraying dyed dispersant. The applied dispersant was collected/measured to document the quality of the application in terms of application rates (L/ha), dispersant droplet size, spray pattern and spray width, influence of the flying conditions (e.g., spraying altitude). A large part of this information can be hardly obtained from sea trials. Such in-land field trials were implemented in several countries (UK, France, US, Norway and Canada) (Additional file 1: Table S1) mainly in the eighties and later in the $90 \mathrm{~s}$ (Lewis and Prince 2018) on different aerial spraying systems (underslung buckets Simplex, Sokaff, Response 3000, planes (Canadair, C130 Hercules, piper Pawnee.). These field trials were implemented often on airfields (and sometimes in fields). Nowadays, these field trials are no longer implemented due to the increasing difficulty of finding testing areas on which spraying dispersant can be accepted. Therefore, unfortunately, the quality of the application and the actual performances of most of the recent operational tools in use (planes and spraying pack systems) is documented only on the technical and/or commercial brochures of manufacturers and/or operators.

\section{Subsea dispersant tests}

Submarine oil discharges had been considered a research topic for a long time, particularly since the 1990s, when the Norwegian carried out experiments on the subject.

Table 2 lists the main field tests completed to understand the behavior of oil and/or gas in the case of subsea oil releases.

Further, the Deepwater Horizon incident sub-sea oil pollutions and the use of dispersants on these pollutions became burning issues, leading to research programs, especially in view of developing laboratory and mesoscale testing methodologies specific to sub-sea situations.

Laboratory studies have been conducted to develop test methods for the reproduction of subsurface conditions (e.g., agitation, dispersant application, etc.), whose results and reproduction rate varied. But the environmental conditions and the oil behaviour at the sea surface and in sub-sea are quite different, especially when the oil source is located very deep (e.g., $800 \mathrm{~m}$ and more). At the time of Deepwater Horizon incident, almost none of the current methods used to assess dispersant efficiency at laboratory and mesoscale stages were designed to reproduce the subsea conditions. However, during Deepwater Horizon incident, due to the lack of specific methods, responders and associated scientists used the regular laboratory testing methods to check which dispersant was appropriate. This approach assumed that a good dispersant for surface situation should also be good in deep sea situation. Using the usual laboratory testing methods, particularly the swirling and baffled tests, it was found that Macondo fresh oil required only a very low DOR (between 1 and $2 \%)$ to be dispersed.

Thereafter, the trend was to develop new specific methodologies to assess the sub-sea dispersion. As the goal of the sub-sea dispersion is to achieve a stable plume of dispersed oil in the water column, the oil droplet size became the main parameter to be assessed using a particle size analysers (e.g. LISST-100) or special camera (e.g.

Table 2 Main field trials completed on oil or gas sub-sea releases (Guyomarch 2002)

\begin{tabular}{|c|c|c|c|c|}
\hline Date & Field test name & Objective & Description & Observations \\
\hline 1975 & Topham & $\begin{array}{l}\text { Check-up of OILMAP model } \\
\text { predictions }\end{array}$ & Release of air from $60 \mathrm{~m}$ deep & \\
\hline 1983 & Milgram & - & Gas release from 50 m deep & \\
\hline 1995 & $\begin{array}{l}\text { Norwegian sea trials (Brandvik } \\
\text { et al. 1996) }\end{array}$ & Pipeline rupture Simulation & $\begin{array}{l}\text { Low pressure oil release from } \\
100 \mathrm{~m} \text { deep }\end{array}$ & $\begin{array}{l}\text { Large oil droplets which reached } \\
\text { the sea surface quickly }\end{array}$ \\
\hline 1996 & $\begin{array}{l}\text { Norwegian sea trials (Rye and } \\
\text { Brandvik 1997) }\end{array}$ & Sub-sea blowout simulation & $\begin{array}{l}\text { High pressure oil }\left(60 \mathrm{~m}^{3}\right) \text { with air } \\
\text { release from } 102 \mathrm{~m} \text { deep }\end{array}$ & $\begin{array}{l}\text { Small oil droplets } \\
\text { Natural dispersion (only 10-20\% of } \\
\text { oil reached the sea surface) }\end{array}$ \\
\hline 2000 & Deep Spill (Johansen et al. 2001) & Sub-sea blowout simulation & $\begin{array}{l}4 \text { releases (oil, seawater, gas) from } \\
850 \mathrm{~m} \text { deep }\end{array}$ & $\begin{array}{l}\text { Total dissolution of gas in the water } \\
\text { column } \\
\text { Oil reaches the surface in one hour }\end{array}$ \\
\hline
\end{tabular}


Sintef's Silhouette Camera (Brandvik et al. 2017b). The testing methods developed for subsea dispersion tried to simulate the prevailing conditions in a deep-sea blowout, particularly for a turbulent release of the oil in a calm environment. However, it is exceedingly difficult to simulate the ambient high pressure at deep sea (e.g., $100 \mathrm{Bar}$ for $1000 \mathrm{~m}$ depth), due to the requirement of the heavy and costly pressurised enclosures and potential security problems.

They are many high-pressure chambers designed for oceanographic or engineering purposes. However, their limited volume restricts the scale of experiments, limiting, the possibilities of studying the development of the dispersed plume as well as its stability. In addition, it is often not allowed to introduce target contaminants (e.g., crude oils) into these technologic devices. At last, the introduction of gas makes an additional difficulty in terms of security. For the above-mentioned reasons, most of the sub-sea dispersion experiments were completed at ambient atmospheric pressure and often without gas, or, using a neutral gas, such as Nitrogen to simulate the conditions of a sub-sea blowout.

\section{Conclusion and future perspectives}

Mesco- and field scale tests, though at a relatively high cost, could provide relatively representative energy conditions in the field and reduce the factors (e.g., wall effect) that could affect the dispersant effectiveness. A proper experimental design, a well-developed experiment and sampling protocol, together with a reasonable result interpretation could provide valuable information for the evaluation of dispersant effectiveness and predication of the transportation and fate of spilled oils. Studies of actual spills (spills of opportunity) could also help reveal processes that influence oil fate and transport beyond those incorporated into current models and laboratory experiments. Since the DWH spill, models have been developed to better represent the processes determining droplet size and transport for both surface and subsurface spills. However, sources of uncertainty remain, including processes such as tip streaming, pressure gradients, and out-gassing. Therefore, additional modeling and field-scale experimentation will be required for more accurate predictions of oil fate and transport. Because it can be difficult to obtain permits for experimental field studies, a spill of opportunity is another option for obtaining the observations necessary to improve models. A spill of opportunity involves being prepared and coordinated in advance, so that should a spill occur, scientists are able to collect samples and data. Any field-scale study will be inherently restricted because of logistical challenges and open boundaries. Thus, it would be highly desirable to develop a large-scale laboratory facility with the ability to include high ambient pressure and observation of droplets as they evolve over time. Further, the warming climate urges research activities on the effects of temperature and ice on dispersed oil droplet size, coalescence, and resurfacing. Continuous research efforts on the fate and behaviours of spilled oil in future climates, with a changing seasonal ice coverage at waters, are also needed. Such information is key to evaluate the effectiveness of dispersants under given cold environmental conditions. As previously discussed, these investigations would probably be more realistic in large wave tanks where dilution more closely approximates natural conditions.

Further, the importance of communication with the public and affected parties to minimize negative perceptions should be recognized, particularly in large spill incidents, such as the Deepwater Horizon incident. The communication strategy was further focused on public engagement in chemical dispersion since such practice was firstly applied underwater, and in a vast amount. Therefore, the reasons and rationales for dispersant application, the monitoring process during the application, as well as the outcomes (e.g., the health and environmental data on the USEPA website) were shared with the public to meet their demand for information. Despite these best efforts, under communication, such as insufficient and/or inappropriate information, and lack of understanding in the complex science and uncertainty, remains to be a challenge that could trigger public concerns and trust issues. Dispersants have been widely studied over the past 30 years with extensive scientific findings that are published in peer-reviewed journals, reports, conferences, such information, however, was not easily available or understandable to the general public due to complex scripts and scientific terms. A better information delivery strategy, better engagement, and risk-based communications are needed to promote the public perception towards dispersant usage.

\section{Abbreviations}

COOGER: Centre for Offshore Oil, Gas and Energy Research; DE: Dispersion effectiveness; DFO: Fisheries and Oceans Canada; DOR: Dispersant to oil ratio; GC-MS: Gas chromatography-mass spectrometry; GOR: Gas to oil ratio; IR: Infrared; IFP: French Institute for Petroleum; OMA: Oil-mineral aggregates; SSDI: Subsea dispersants injection; SwRI: Southwest Research Institute; UV: Ultraviolet; WAF: Water accommodated fraction.

\section{Supplementary Information}

The online version contains supplementary material available at https://doi. org/10.1186/s40068-021-00241-5.

Additional file 1: Table S1. A review of previous field trials. 


\section{Acknowledgements}

This work was supported by Fisheries and Oceans Canada (DFO) under the Multi-Partner Research Initiative (MPRI) program.

\section{Authors' contributions}

FM and BZ conceived and designed the review; FM, ZZ, and MY collected, analyzed, and interpreted the data; and drafted this manuscript; $\mathrm{BZ}, \mathrm{KL}, \mathrm{BC}$ refined the methodology, provided support in collecting additional literature; $\mathrm{BZ}, \mathrm{KL}, \mathrm{BC}, \mathrm{LI}, \mathrm{MB}$ provided critical comments and feedback and edited this manuscript. All authors read and approved the final manuscript.

\section{Funding}

This work was supported by Fisheries and Oceans Canada (DFO) under the Multi-Partner Research Initiative (MPRI) program.

\section{Availability of data and material}

Not applicable.

\section{Declarations}

Ethics approval and consent to participate

Not applicable.

\section{Consent for publication}

All authors read and approved the final manuscript and mutually agreed that it should be submitted to Environmental System Research.

\section{Competing interests}

The authors have no conflicts of interest to declare.

\section{Author details}

${ }^{1}$ Northern Region Persistent Organic Pollutant Control (NRPOP) Laboratory, Faculty of Engineering and Applied Science, Memorial University, St. John's, NL A1B 3X5, Canada. ${ }^{2}$ Oil Spill Response Consultant, Freelance, 29200 Brest, France. ${ }^{3}$ Fisheries and Oceans Canada, Ecosystem Science, Ottawa, ON K1A OE6, Canada. ${ }^{4}$ Center for Natural Resources, Department of Civil and Environmental Engineering, New Jersey Institute of Technology, Newark, NJ 07102, USA.

Received: 5 May 2021 Accepted: 19 July 2021

Published online: 03 August 2021

\section{References}

Aprin L, Heymes F, Cosenza M, Lauret P, Slangen P, Le Floch S (2016) Experimental study of submerged leakage from a shipwreck involving floating chemicals cargo. Chem Eng Trans 53:343-348

Baszanowska E, Otremba Z (2019) Detecting the presence of different types of oil in seawater using a fluorometric index. Sensors 19(17):3774

Bejarano AC (2018) Critical review and analysis of aquatic toxicity data on oil spill dispersants. Environ Toxicol Chem 37(12):2989-3001

Bi H, An C, Owens E, Lee K, Chen Z, Mulligan C, Taylor E, Boufadel M (2021) A framework for the evaluation and selection of shoreline surface washing agents in oil spill response. J Environ Manag 287:112346

Boufadel M, Pan Z, Wartell B, Steffek T, Guarino A (2017) Chemical characterization of the Ohmsett tank water: filtration and potential impact on dispersion effectiveness, 40th Arctic and Marine Oilspill Program-Technical Seminar on Environmental Contamination and Response, AMOP 2017

Brandvik P, Strom-Kristiansen T, Jensen H, Lewis A, Daling P, Reed M, Rye H (1996), The Norwegian Sea Trial 1995 Offshore Testing of Two Dispersant Application Systems and Simulation of an Underwater Pipeline Leakage: A Summary Paper, Aarctic and marine oilspill program technical seminar, ministry of supply and services, canada, pp. 1395-1416

Brandvik PJ, Johansen Ø, Leirvik F, Farooq U, Daling PS (2013) Droplet breakup in subsurface oil releases-part 1: experimental study of droplet breakup and effectiveness of dispersant injection. Mar Pollut Bull 73:319-326

Brandvik PJ, Johansen Ø, Farooq U (2014) Subsea release of oil \& gas-a downscaled laboratory study focused on initial droplet formation and the effect of dispersant injection, International Oil Spill Conference Proceedings, American Petroleum Institute, pp. 283-298

Brandvik P, Davies E, Bradly C, Storey C, Leirvik F (2016) Subsurface Oil Releases-Verification of Dispersant Effectiveness under High Pressure, Sintef Materials and Chemistry Report A27469, January 01, 2016. Subsea Dispersant Injection-Summary of Operationally Relevant Findings from a Multi-year Industry Initiative, SPE International Conference and Exhibition on Health, Safety, Security, Environment, and Social Responsibility, pp. $11-13$

Brandvik P, Davies E, Johansen Ø, Leirvik F, Belore R (2017a) Subsea Dispersant Injection-Large-Scale Experiments to Improve Algorithms for Initial Droplet Formation (Modified Weber Scaling); An approach using the Ohmsett facility, NJ, USA and SINTEF Tower Basin in Norway (UNRESTRICTED), An Approach Using the Ohmsett Facility, NJ, USA and SINTEF Tower Basin in Norway. SINTEF Report No: OC2017 A-087. Trondheim Norway

Brandvik P, Johansen $\varnothing$, Davies E, Leirvik F, Krause D, Daling P, Dunnebier D, Masutani S, Nagamine I, Storey C (2017b), Subsea dispersant injection (SSDI)-summary findings from a multi-year research and development industry initiative, International Oil Spill Conference Proceedings, International Oil Spill Conference, pp. 2762-2790

Brandvik PJ, Johansen Ø, Leirvik F, Krause DF, Daling PS (2018) Subsea dispersants injection (SSDI), effectiveness of different dispersant injection techniques-an experimental approach. Mar Pollut Bull 136:385-393

Brandvik PJ, Daling PS, Leirvik F, Krause DF (2019a) Interfacial tension between oil and seawater as a function of dispersant dosage. Mar Pollut Bull 143:109-114

Brandvik PJ, Storey C, Davies EJ, Johansen $\varnothing$ (2019b) Combined releases of oil and gas under pressure; the influence of live oil and natural gas on initial oil droplet formation. Mar Pollut Bull 140:485-492

Brandvik PJ, Storey C, Davies EJ, Leirvik F (2019c) Quantification of oil droplets under high pressure laboratory experiments simulating deep water oil releases and subsea dispersants injection (SSDI). Mar Pollut Bull 138:520-525

Brandvik PJ, Davies E, Leirvik F, Johansen $\varnothing$, Belore R (2021) Large-scale basin testing to simulate realistic oil droplet distributions from subsea release of oil and the effect of subsea dispersant injection. Marine Pollution Bull 163:111934

Cai Q, Zhu Z, Chen B, Lee K, Nedwed TJ, Greer C, Zhang B (2021) A Cross-comparison of biosurfactants as marine oil spill dispersants: governing factors, synergetic effects and fates. J Hazard Mater 416:126122

Cedre (2014) Flume tank, Cedre Information Bulletin No 32 Centre of Documentation, Research and Experimentation on Accidental Water Pollution

Chapman H, Purnell K, Law RJ, Kirby MF (2007) The use of chemical dispersants to combat oil spills at sea: a review of practice and research needs in Europe. Mar Pollut Bull 54:827-838

Colcomb K, Salt D, Peddar M, Lewis A (2005) Determination of the limiting oil viscosity for chemical dispersion at sea. Int Oil Spill Conference Am Petroleum Institute 2005:53-58

Cui F, Geng X, Robinson B, King T, Lee K, Boufadel MC (2020) Oil droplet dispersion under a deep-water plunging breaker: experimental measurement and numerical modeling. J Marine Sci Eng 8(4):230

Cyr F, Tedetti M, Besson F, Bhairy N, Goutx M (2019) A glider-compatible optical sensor for the detection of polycyclic aromatic hydrocarbons in the marine environment. Front Mar Sci 6:110

Daling PS, Singsaas I, Reed M, Hansen O (2002) Experiences in dispersant treatment of experimental oil spills. Spill Sci Technol Bull 7(5-6):201-213

Delacroix S, Germain G, Gaurier B, Billard J-Y (2016) Experimental study of bubble sweep-down in wave and current circulating tank: part I-experimental set-up and observed phenomena. Ocean Eng 120:78-87

Desmarquest J, Croquette J, Merlin F, Bocard C, Gatellier C (1983) A field test and assessment of oil dispersant efficiency. Int Oil Spill Conference Am Petroleum Institute 1983:574-574

Duan Z, Li Y, Wang J, Zhao G, Svanberg S (2019) Aquatic environment monitoring using a drone-based fluorosensor. Appl Phys B 125(6):1-8

Even ASLF (2003) Détermination de la solubilité du styrène en fonction de la température et de la salinité de la colonne d'eau. Study report, CEDRE

Faksness LG, Brandvik PJ, Daling PS, Singsaas I, Sørstrøm SE (2016) The value of offshore field experiments in oil spill technology development for Norwegian waters. Mar Pollut Bull 111(1-2):402-410 
Faksness L-G, Belore RC, McCourt J, Johnsen M, Pettersen T-A, Daling PS (2017) Effectiveness of chemical dispersants used in broken ice conditions. Int Oil Spill Conference Proc 2017:1543-1558

Fingas M (2014) Handbook of oil spill science and technology. Wiley

Gill S, Ross C (1981) dispersant application field trial—St. John's Newfoundland, Proc. 5th Arctic Marine Oilspill Program Technical Seminar. Ottawa: Environment Canada, pp. 255-263

Gill S, Goodman R, Swiss J (1985) Halifax'83 sea trial of oil spill dispersant concentrates, International Oil Spill Conference, American Petroleum Institute, pp. 479-482

Gomaa EZ (2013) Antimicrobial activity of a biosurfactant produced by Bacillus licheniformis strain M104 grown on whey. Braz Arch Biol Technol 56:259-268

Guyomarch MFJ (2002) Comportement et devenir des hydrocarbures dans une eruption sous-marine à grande profondeur, Cedre

Guyomarch J, Le Floch S, Jezequel R (2012) Oil Weathering, Impact Assessment and Response Options Studies at the Pilot Scale: Improved Methodology and Design of a New Dedicated Flume Test, Proceedings of the 35th Arctic and Marine Oilspill Program Technical Seminar on Environmental Contamination and Response, pp. 1001-1017

Holder EL, Conmy RN, Venosa AD (2015) Comparative laboratory-scale testing of dispersant effectiveness of 23 crude oils using four different testing protocols. J Environ Prot 6:628

Jézéquel R, Receveur J, Nedwed T, Le Floch S (2018) Evaluation of the ability of calcite, bentonite and barite to enhance oil dispersion under arctic conditions. Mar Pollut Bull 127:626-636

Johansen $\varnothing$, Rye H, Melbye AG, Jensen HV, Serigstad B, Knutsen T (2001) Deep spill JIP-Experimental discharges of gas and oil at Helland Hansen-June 2000. SINTEF Rep. 5TF66 F01082, pp 1-159

King T, Robinson B, Ryan S, Lee K, Boufadel M, Clyburne J (2018) Estimating the usefulness of chemical dispersant to treat surface spills of oil sands products. J Marine Sci Eng 6:128

Lambert P (2003) A literature review of portable fluorescence-based oil-inwater monitors. J Hazard Mater 102:39-55

Lewis MA (2005) UK sea trials with dispersants, Analysis of new opportunities for usage of dispersants in the Baltic Sea, Riga, Latvia

Lewis A, Prince RC (2018) Integrating dispersants in oil spill response in Arctic and other icy environments. Environ Sci Technol 52(11):6098-6112

Li Z, Spaulding ML, French-McCay D (2017) An algorithm for modeling entrainment and naturally and chemically dispersed oil droplet size distribution under surface breaking wave conditions. Mar Pollut Bull 119(1):145-152

Malone K, Pesch S, Schlüter M, Krause D (2018) Oil droplet size distributions in deep-sea blowouts: influence of pressure and dissolved gases. Environ Sci Technol 52:6326-6333

Merlin FX, Peigné G (2007) Oil spill response at sea T 2.4 Use of dispersants: state of the art Rev 1

Merlin FX (2008) French sea trials on chemical dispersion: DEPOL 04 \& 05, Oil Spill Response: a Global Perspective, Springer, pp. 119-140

Merlin FX, de Nanteuil E, Guyomarch J (2006) SEA TRIALS ON CHEMICAL DISPERSION «DEPOL 04». Interspill. Cedre, Brest, France, London

National Academies of Sciences E \& Medicine (2005) Oil spill dispersants: efficacy and effects, National Academies Press

National Academies of Sciences, E \& Medicine (2020) The Use of Dispersants in Marine Oil Spill Response, Washington, DC, The National Academies Press, p. 340
Nedwed T, Coolbaugh T, Canevari GP, Clark J, Tidwell A, Owens E (2011) Calm Seas Dispersant Use, International Oil Spill Conference Proceedings (IOSC), American Petroleum Institute, p. abs246

O'Laughlin CM, Law BA, Zions VS, King TL, Robinson B, Wu Y (2017) Settling of dilbit-derived oil-mineral aggregates (OMAs) \& transport parameters for oil spill modelling. Mar Pollut Bull 124:292-302

Pesch S, Jaeger P, Jaggi A, Malone K, Hoffmann M, Krause D, Oldenburg TB, Schlüter M (2018) Rise velocity of live-oil droplets in deep-sea oil spills. Environ Eng Sci 35:289-299

Rye H, Brandvik PJ (1997) Verification of subsurface oil spill models. In: International Oil Spill Conference, vol 1997, No 1. American Petroleum Institute, pp 551-557

Ross SL (2013) Comparison of Small-Scale Dispersant Testing Methods to Ohmsett: Effect of Dispersant Type and Oil Properties, S.L. Ross Environmental Research Ltd

Song X, Jing L, Chen B, Zhu Z, Cai Q, Ye X, Zheng X, Hill SJ, Zhang B (2021) The effect of pressure variation on droplet size distribution of dispersed oil under simulated deep-water conditions. Heliyon 7(3):e06291

Steffek T, Bittler K, Guarino A (2017) Large scale comparative testing of corexit EC9500A, Finasol OSR 52, Accell Clean DWD, Marine D-Blue Clean, and ZI 400 at Ohmsett. Int Oil Spill Conference Proc 2017:347-361

Stéphane LF, Hosna B, René O (2009) Operational device and procedure to test the initial dissolution rate of chemicals after ship accidents: the Cedre Experimental Column. Open Environ Pollution Toxicol J 1:1

Vahabisani A, An C (2021) Use of biomass-derived adsorbents for the removal of petroleum pollutants from water: a mini-review. Environ Syst Res 10(1):1-10

Vanganse S, Le FLOCH S, Mauge R, Aprin L (2013) Influence of dispersant addition on the rise of oil droplets contributions to modelling, Proceedings of the 36th AMOP Technical Seminar on Environmental Contamination and Response, pp. 315-325

Venosa AD, Kaku VJ, Boufadel MC, Lee K (2005) Measuring energy dissipation rates in a wave tank, International Oil Spill Conference, American Petroleum Institute, pp. 183-186

Yang M, Chen B, Xin X, Song X, Liu J, Dong G, Lee K, Zhang B (2020) Interactions between microplastics and oil dispersion in the marine environment. J Hazard Mater 403:23944

Zhao L, Shaffer F, Robinson B, King T, D'Ambrose C, Pan Z, Gao F, Miller RS, Conmy RN, Boufadel MC (2016) Underwater oil jet: hydrodynamics and droplet size distribution. Chem Eng J 299:292-303

Zhao L, Gao F, Boufadel MC, King T, Robinson B, Lee K, Conmy R (2017) Oil jet with dispersant: macro-scale hydrodynamics and tip streaming. AIChE J 63:5222-5234

Zhu Z, Zhang B, Cai Q, Ling J, Lee K, Chen B (2020) Fish waste based lipopeptide production and the potential application as a bio-dispersant for oil spill control. Front Bioeng Biotechnol 8:734

\section{Publisher's Note}

Springer Nature remains neutral with regard to jurisdictional claims in published maps and institutional affiliations.

\section{Submit your manuscript to a SpringerOpen ${ }^{\circ}$ journal and benefit from:}

- Convenient online submission

- Rigorous peer review

- Open access: articles freely available online

- High visibility within the field

Retaining the copyright to your article

Submit your next manuscript at springeropen.com 